\title{
Researhc Paper: The Prevalence of Musculoskeletal Symptoms in Iranian Spinner Workers in the Textile Industry and its Association With Demographic and Lifestyle Characteristics
}

\author{
Akram Shahbazi' ${ }^{1}$, Hamid Reza Mokhtarinia ${ }^{1^{*}}$ (D), Akbar Biglarian² ${ }^{\text {(D) }}$, Charles Philip Gabel ${ }^{3}$ (D) \\ 1. Department of Ergonomics, University of Social Welfare and Rehabilitation Sciences, Tehran, Iran. \\ 2. Department of Biostatistics, Social Determinants of Health Research Center, University of Social Welfare and Rehabilitation Sciences, Tehran, Iran. \\ 3. Access Physiotherapy, Coolum Beach, Sunshine Coast, QLD, Australia.
}

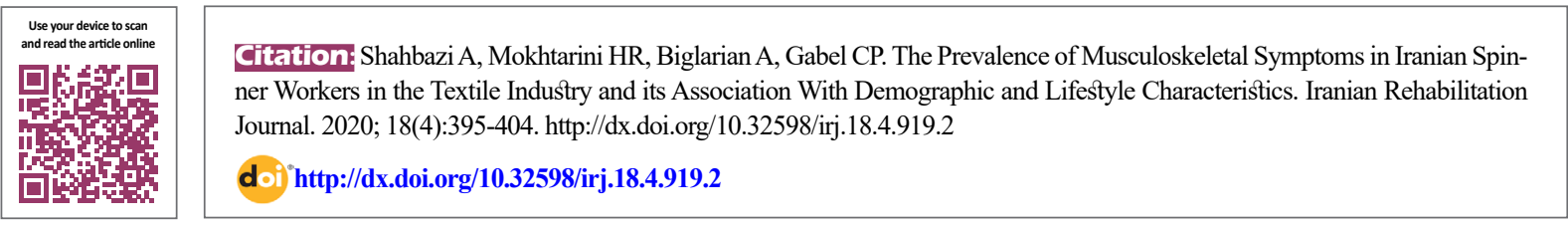

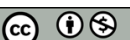

Article info:

Received: 18 May 2020

Accepted: 02 Nov 2020

Available Online: 01 Dec 2020

Keywords:

Prevalence, Spinner workers, Musculoskeletal disorder, Body Mass Index (BMI)

\begin{abstract}
Objectives: This study aimed to identify the annual and weekly prevalence of Musculoskeletal Disorders (MSDs) and their relation to demographic characteristics, such as Body Mass Index (BMI), work experience, and physical activity in spinner workers in the textile industry. We also conducted a comparison between the annual and weekly prevalence of MSDs.

Methods: The study sample included 700 male spinner workers (Mean \pm SD age: $32.6 \pm 6.5$ years) from 10 companies in Najaf Abad City, Isfahan Province, Iran. Information about MSDs was collected through the Extended Nordic Musculoskeletal Questionnaire (ENMQ) from November 2018 to September 2019. Demographic characteristics were collected using a demographic checklist through a direct interview by one investigator.

Results: The present study findings suggested that the Mean \pm SD duration of work hours per week was $56.6 \pm 8.4$ hours. The Mean \pm SD times of experiencing an injury equaled $27.8 \pm 33.1$ months. The annual prevalence of MSDs was reported to be $74.4 \%$ for at least one of the 9 body regions. The highest annual prevalence rates belonged to the knees $(54.0 \%)$, lower back (34.3\%), and shoulders (23.1\%). In contrast, the most weekly prevalent regions were the knees (44.6\%), lower back (26.9\%), and ankles (15.9\%). Generally, the weekly prevalence was significantly lower than that of the annual prevalence $(\mathrm{P}<0.008)$. Job experience, marital status, and physical exercise presented a significant relationship with the annual prevalence of MSDs in the neck, shoulders, elbows, wrists, hands, knees, and ankle/foot. Contrarily, there was a significant relationship between job experience and the weekly prevalence of MSDs in the shoulder, lower back, and knee regions. The prevalence of neck, shoulders, wrists/hands, low back, knee, and ankle/foot pain was significantly increased in married workers. Furthermore, exercise history could cause a significant decrease in the prevalence of MSDs.
\end{abstract}

Discussion: The high prevalence of MSDs in spinner workers is affected by some demographic characteristics; thus, such data should be considered in planning the prevention strategies within the textile industry. 


\section{Highlights}

- MSDs are a relatively prevalent disorder in Iranian spinner workers.

- Musculoskeletal conditions in spinner workers can result in disability; thus, they should be considered in the health and rehabilitation programs.

- To reduce the MSDs prevalence within the textile industry, screening programs based on the demographics and occupational characters should be planned.

- A high prevalence of MSDs in the textile industry in Iran is associated with ergonomic factors.

\section{Plain Language Summary}

Work-Related Musculoskeletal Disorders (WRMDs) have become a major problem in many industrialized countries. Productivity in each industry depends on the individual wellbeing of the workers. A high prevalence of WRMDs in the clothing and textile industry results in low productivity and imposes high demands on the health system. Prevention and rehabilitation programs for reducing the complication of these disorders should be associated with treatment plans, like ergonomic-related interventions.

\section{Introduction}

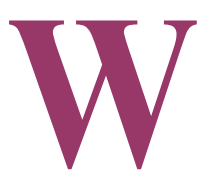

ork-Related Musculoskeletal Disorders (WMSDs) are a sub-category of Musculoskeletal Disorders (MSDs) that result from occupational risk factors. The presence of WMSDs remains a major concern despite decades of investment in its prevention at all levels $[1,2]$. In industrialized and industrially-developing countries, these WMSDs are potentially disabling conditions [1, 3, 4]; they impact the worker's quality of life and productivity, and increases compensable costs $[5,6]$. According to the US Department of Labor, $>500000$ cases of MSDs are reported annually in the USA, accounting for more than a third of all lost workdays [7]. Working day loss due to WMDs in the Great Britain in 2016-2017 was reported to be 8.9 million days [8], which accounts for $34 \%$ of all lost workday injuries and illnesses [9]. In Iran, the Medical Commission of the Social Security Organization of Tehran Province reported that $14.4 \%$ of disabilities was related to MSDs [5] making them the fourth highest cause of disability in Iran [10].

Textile production has a long history in Iran, where the first modern European-style factories were established in the 1850s in Persia [11]. Spinning is a major section of textile industry in which the yarn are produced by twisting of the drawn-out strands of fibers. These industries constitute around $12 \%$ of the general employment in Iran [11] and have approximately 300000 workers directly employed. The major centers of the Iranian textile industry are Isfahan, Yazd, Kerman, and Mazanda- ran Provinces. The spinning industry is susceptible to MSDs, particularly in developing countries, including India, Pakistan, Bangladesh, Iran, Turkey, and China. Besides, these locations remain more traditional due to the age of the devices used, the traditional methods employed, and the nature of the work [12].

A high prevalence of WRMDs, like pain in the neck, shoulder, hand, as well as thoracic and lumbar areas are reported in the clothing and textile industry $[13,14]$. The nature of the spinning industry tasks consists of various repetitive activities in static postures. Furthermore, for some tasks, the activities are completed at different heights with various loads. Generally, repetitive movements of the hand, trunk bending and rotation, overhead/ shoulder activity, pushing/pulling, lifting/lowering of heavy loads, and long periods of standing and walking are observed in the spinning industry $[12,15]$.

Limited studies have been conducted on the prevalence of MSDs in the spinning industry $[13,16,17]$. However, we found no study which had evaluated the relationship between the demographic characteristics and the prevalence of MSDs in spinning workers in a country with a long and established industry. Therefore, the current research aimed to assess the prevalence of MSDs in Iranian spinning workers. We also investigated the relationship between MSDs prevalence and demographic characteristics in Iranian spinning workers. 


\section{Methods}

The present descriptive cross-sectional study was conducted on 700 spinner workers. The study participants were selected through a simple random sampling method from 10 factories in Najaf Abad City, Isfahan Province, Iran. The necessary data were gathered from November 2018 to September 2019. The inclusion criteria of the study included a job experience of $>1$ year, the age range of 20-50 years, and a minimum middle school degree education. Subjects with a history of surgery, any traumatic injury that results in dysfunction, and psychosocial problems, like depression, and those who refused to participate in the research were excluded from the study. All data related to the health status of the study subjects were extracted from their medical records. The main tasks selected for analysis were ring spinning operation, carding operation, blending and spinning tasks, as well as machine operation. This research was approved by the Ethics Committee of University of Social welfare and Rehabilitation Sciences, Tehran, Iran (Code: IR.USWR. REC.1397.133). A written informed consent form was provided by each research subject.

In this study, the workplace-related and demographic characteristics of the study participants were collected by a checklist. Additionally, the Extended Nordic Musculoskeletal Questionnaire (ENMQ) was used to assess MSDs in different body regions among the explored spinner workers. Both instruments were completed inperson and through interview by one researcher (A.Sh). The psychometric properties of the Persian version of the ENMQ were previously established [18] with acceptable face validity for all items. Its reliability was evaluated through the intraclass correlation coefficient method $(>0.7)$ and the standard error of measurement range (0.56-1.76) [18]. The EMNQ consists of a body diagram with 9 anatomical regions highlighted. For each region, the subject indicates the presence of pain or discomfort up till that time. For any region with pain or discomfort, the subject then indicates whether the pain interferes with his/her daily living activities, or if they had been hospitalized for that problem. Two later questions ask whether they had a pain or discomfort in each region, respectively, in the past 12 months, and past 4 weeks [19]. The results of the EMNQ determine the prevalence rate of symptoms per the 9 body regions, annually and weekly $[18,20]$.

The study samples' demographic data were collected using a checklist, including independent variables, i.e. age, smoking history, Body Mass Index (BMI), exercise habits (not regularly, regularly for 2-3 days per week), educational level, marital status, job experience, and work hours per day. The annual and weekly prevalence of MSDs were considered as dependent variables, i.e. determined using the ENMQ questionnaire. Descriptive and inferential statistical methods were used to analyze the obtained data. The Independent Samples t-test and logistic regression were employed in SPSS for data analysis. $\mathrm{P}<0.05$ was considered as the significance level.

\section{Results}

We collected the data of 700 eligible male spinner workers from 10 different factories in Najafabad City, Isfahan Province, Iran. A summary of the demographic characteristics of the independent variables was determined (Table 1). The Mean \pm SD age of the study participants was $32.6 \pm 6.5$ years. Besides, their Mean \pm SD duration of work hours per week equaled $56.6 \pm 8.4$ hours. Moreover, the Mean \pm SD time of experiencing an injury was measured as $27.8 \pm 33.1$ months. Most workers were over 30 years of age $(62.7 \%)$ with a job history of $>5$ $(55.6 \%)$ years. Besides, their Mean \pm SD job experience was calculated to be $8.2 \pm 6.1$ years.

Almost three quarters $(74.4 \%$ or 521 workers) of the study participants reported that MSDs had troubled them in one or more of the 9 defined body regions in the past 12 months. A total of $22.5 \%$ study subjects reported symptoms in one region, $21.9 \%$ in two regions, $14.5 \%$ in three regions, $7.7 \%$ in 4 regions, $4.7 \%$ in 5 regions, $2.1 \%$ in 6 regions, $0.3 . \%$ in 7 regions, $0.6 \%$ in 8 regions, and $0.3 \%$ in all 9 regions. The annual and weekly prevalence of MSDs by the 9 anatomical regions are presented in Table 2 .

As per Table 2, the regions with the highest annual prevalence among the investigated spinner workers were the knees $(54.0 \%)$, lower back (34.3\%), and shoulders $(23.1 \%)$. In contrast, the highest weekly prevalent musculoskeletal symptoms were the knees $(44.6 \%)$, lower back (26.9\%), and ankles (15.9\%).

Accordingly to Table 2, though the weekly and annual prevalence were almost the same, the test of significance (two dependent groups) revealed the weekly prevalence as significantly lower than that of the annual status $(\mathrm{P}<0.008)$. The consequence of this significant difference is that the factors affecting musculoskeletal symptoms in both periods were analyzed separately, as reported below.

The logistic regression analysis data of one-year prevalent musculoskeletal symptoms are discussed as follows: 
Table 1. The demographic characteristics of the study subjects $(\mathrm{N}=700)$

\begin{tabular}{|c|c|c|c|}
\hline Characteristic & Mean $\pm S D$ & Status & No. (\%) \\
\hline \multirow{3}{*}{ Age $(y)$} & & $<30$ & $261(37.3)$ \\
\hline & $32.6 \pm 6.5$ & & \\
\hline & & $\geq 30$ & $439(62.7)$ \\
\hline \multirow{3}{*}{ Smoking history } & & Yes & $49(7.0)$ \\
\hline & & & \\
\hline & & No & $651(93.0)$ \\
\hline \multirow{3}{*}{$\mathrm{BMI}\left(\mathrm{kg} / \mathrm{m}^{2}\right)$} & & $25 \geq$ & $420(60.0)$ \\
\hline & $24.2 \pm 3.7$ & & \\
\hline & & $>25$ & $280(40.0)$ \\
\hline \multirow{3}{*}{ Exercise habits } & & Often or sometimes & $284(40.6)$ \\
\hline & & & \\
\hline & & Never & $416(59.4)$ \\
\hline \multirow{3}{*}{ Educational status } & & No diploma & $253(36.1)$ \\
\hline & & Diploma and below BA & $417(59.6)$ \\
\hline & & BA degree and higher & $30(4.3)$ \\
\hline \multirow{3}{*}{ Marital status } & & Single & 139 (19.9) \\
\hline & & & \\
\hline & & Married & $561(80.1)$ \\
\hline \multirow{3}{*}{ Injury experience (m) } & & No injury experience & $179(25.6)$ \\
\hline & $27.8 \pm 33.1$ & & \\
\hline & & Having injury experience & $521(74.4)$ \\
\hline \multirow{3}{*}{ Job experience (y) } & & $5 \geq$ & $311(44.4)$ \\
\hline & $8.2 \pm 6.1$ & & \\
\hline & & $5<$ & $389(55.6)$ \\
\hline
\end{tabular}

Iranian Rehabilitation Journal

Table 2. The one-year and weekly prevalence rates of MSDs in the studied workers by anatomical regions

\begin{tabular}{ccc}
\hline \multirow{2}{*}{ Anatomical Regions } & & No. (\%) \\
\cline { 2 - 3 } Neck & Annual Prevalence & Weekly Prevalence \\
\hline Shoulders & $119(17.0)$ & $90(12.9)$ \\
\hline Elbows & $162(23.1)$ & $109(15.6)$ \\
\hline Wrist/hands & $52(7.4)$ & $38(5.4)$ \\
\hline Upper back & $101(14.4)$ & $79(11.3)$ \\
\hline Lower back & $77(11.0)$ & $56(8.0)$ \\
\hline Thigh & $240(34.3)$ & $188(26.9)$ \\
\hline Knee & $45(6.4)$ & $38(5.4)$ \\
\hline Ankle/foot & $378(54.0)$ & $312(44.6)$ \\
\hline
\end{tabular}


Table 3. Characteristics associated with the annual prevalence of musculoskeletal symptoms

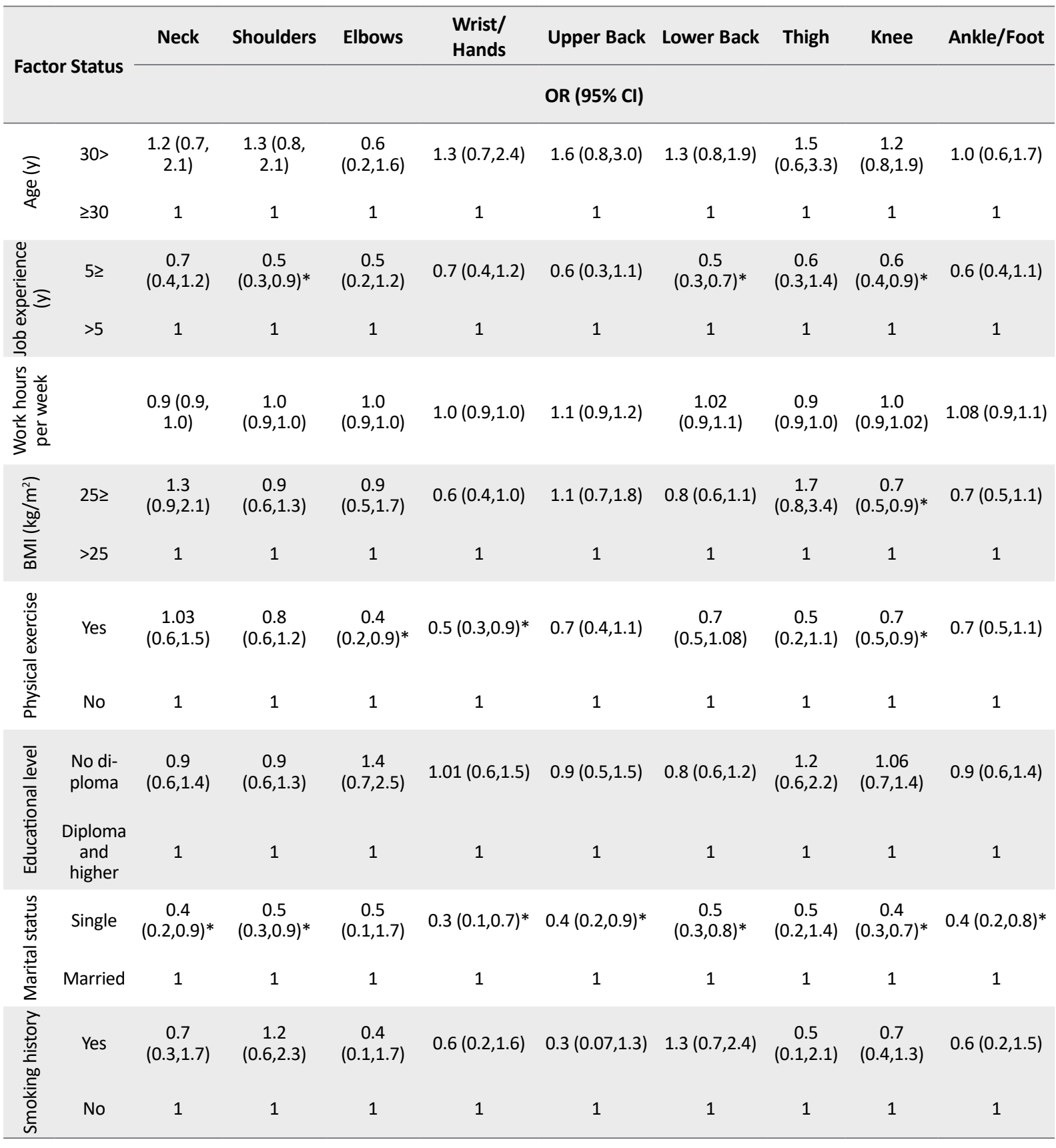

*P<0.05.

Iranian Rehabilitation Dourna

Table 3 lists the relations between the annual prevalence of musculoskeletal symptoms and demographic variables. Our results indicated a significant difference between different factors' status and prevalence in different body regions. The obtained P-value for neck discomfort in various marital status was equal to 0.02 ; the same value for shoulders in different work experience and marital status was 0.017 and 0.034 , respectively; for elbows in different physical exercise status was 0.024 ; for wrists/hands in different marital status and physi- cal exercise was 0.009 and 0.027 , respectively; for the knee in different work experience, marital status, BMI, and physical exercise was $0.018,0.001$, and 0.036 , and 0.038 , and the $\mathrm{P}$-value for ankle/foot in different marital status was measured as 0.019 .

Table 3 presents a significant relationship between work experience, marital status, and physical exercise, and the annual MSDs prevalence. No significant difference was observed between the annual prevalence of musculoskeletal discomfort and other demographic 
Table 4. Factors associated with the weekly prevalence of musculoskeletal symptoms in the study subjects

\begin{tabular}{|c|c|c|c|c|c|c|c|c|c|c|}
\hline \multicolumn{2}{|c|}{ Factor Status } & Neck & $\begin{array}{l}\text { Shoul- } \\
\text { ders }\end{array}$ & Elbows & $\begin{array}{l}\text { Wrist/ } \\
\text { Hands }\end{array}$ & Upper Back & Lower Back & Thigh & Knee & Ankle/Foot \\
\hline & & \multicolumn{9}{|c|}{ OR (95\% Cl) } \\
\hline \multirow{2}{*}{$\begin{array}{l}\bar{z} \\
0 \\
\stackrel{0}{00}\end{array}$} & $30>$ & $\begin{array}{c}1.4 \\
(0.8,2.6)\end{array}$ & $\begin{array}{c}1.5(0.8 \\
2.6)\end{array}$ & $\begin{array}{c}0.5(0.2 \\
1.6)\end{array}$ & $1.3(0.7,2.5)$ & $\begin{array}{c}1.5(0.7 \\
3.2)\end{array}$ & $1.2(0.0,2.1)$ & $\begin{array}{c}1.2 \\
(0.5 \\
3)\end{array}$ & $\begin{array}{c}1.1 \\
(0.7,1.6)\end{array}$ & $\begin{array}{c}0.9(0.5 \\
1.6)\end{array}$ \\
\hline & $\geq 30$ & 1 & 1 & 1 & 1 & 1 & 1 & 1 & 1 & 1 \\
\hline \multirow{2}{*}{ 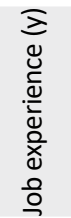 } & $5 \geq$ & $\begin{array}{c}0.8(0.5 \\
1.5)\end{array}$ & $\begin{array}{c}0.5(0.3 \\
0.9)^{*}\end{array}$ & $\begin{array}{c}0.4(0.1 \\
1.2)\end{array}$ & $0.7(0.4,1.3)$ & $\begin{array}{c}0.6(0.3 \\
1.2)\end{array}$ & $\begin{array}{c}0.4(0.3 \\
0.7)^{*}\end{array}$ & $\begin{array}{c}0.7 \\
(0.3 \\
1.6)\end{array}$ & $\begin{array}{c}0.6 \\
(0.4,0.8)^{*}\end{array}$ & $\begin{array}{c}0.6(0.4 \\
1.1)\end{array}$ \\
\hline & $>5$ & 1 & 1 & 1 & 1 & 1 & 1 & 1 & 1 & 1 \\
\hline \multicolumn{2}{|l|}{ 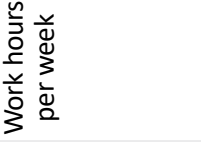 } & $\begin{array}{c}1(0.9 \\
1.02)\end{array}$ & $\begin{array}{c}1.0(0.9 \\
1.1)\end{array}$ & $\begin{array}{c}1.03(1.01 \\
1.1)^{*}\end{array}$ & $\begin{array}{c}1.05(0.9 \\
1.1)\end{array}$ & $1(0.9,1.03)$ & $\begin{array}{c}1.05 \\
(0.9,1.1)\end{array}$ & $\begin{array}{c}0.9 \\
(0.9 \\
1)\end{array}$ & $1(0.9,1.1)$ & $\begin{array}{c}1.09(0.9 \\
1.1)\end{array}$ \\
\hline \multirow{2}{*}{ 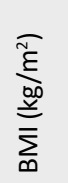 } & $25 \geq$ & $\begin{array}{c}1.3(0.8 \\
2.1)\end{array}$ & $\begin{array}{c}0.7(0.5 \\
1.1)\end{array}$ & $\begin{array}{c}0.9(0.4 \\
1.9)\end{array}$ & $\begin{array}{c}0.6(0.3 \\
1.02)\end{array}$ & $\begin{array}{c}0.9(0.5 \\
1.4)\end{array}$ & $\begin{array}{c}0.91(0.6 \\
1.3)\end{array}$ & $\begin{array}{l}1.3 \\
(0.6 \\
2.7)\end{array}$ & $\begin{array}{c}0.8 \\
(0.5,1.1)\end{array}$ & $\begin{array}{c}0.8(0.5 \\
1.2)\end{array}$ \\
\hline & $>25$ & 1 & 1 & 1 & 1 & 1 & 1 & 1 & 1 & 1 \\
\hline \multirow{2}{*}{ 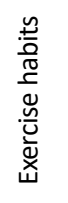 } & Yes & $\begin{array}{c}0.9(0.5 \\
1.4)\end{array}$ & $\begin{array}{c}0.9(0.6 \\
1.5)\end{array}$ & $\begin{array}{c}0.3(0.1 \\
0.8)^{*}\end{array}$ & $0.6(0.4,1.1)$ & $\begin{array}{c}0.8(0.4 \\
1.4)\end{array}$ & $0.8(0.5,1.2)$ & $\begin{array}{c}0.3 \\
(0.1 \\
0.8)^{*}\end{array}$ & $\begin{array}{c}0.6 \\
(0.5,0.9)^{*}\end{array}$ & $0.7(0.4,1)$ \\
\hline & No & 1 & 1 & 1 & 1 & 1 & 1 & 1 & 1 & 1 \\
\hline \multirow{2}{*}{ 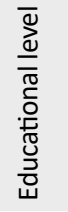 } & $\begin{array}{l}\text { No di- } \\
\text { ploma }\end{array}$ & $\begin{array}{l}1.04 \\
(0.6, \\
1.6)\end{array}$ & $\begin{array}{c}1.1(0.7 \\
1.8)\end{array}$ & $\begin{array}{c}1.4(0.7 \\
2.9)\end{array}$ & $1.1(0.7,1.9)$ & $\begin{array}{c}1.3(0.7 \\
2.3)\end{array}$ & $0.8(0.6,1.2)$ & $\begin{array}{c}1.1 \\
(0.5 \\
2.3)\end{array}$ & $\begin{array}{c}0.9 \\
(0.6,1.2)\end{array}$ & $1(0.7,1.6)$ \\
\hline & $\begin{array}{l}\text { Diploma } \\
\text { and } \\
\text { higher }\end{array}$ & 1 & 1 & 1 & 1 & 1 & 1 & 1 & 1 & 1 \\
\hline \multirow{2}{*}{ 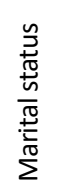 } & Single & $\begin{array}{c}0.4(0.2 \\
0.9)^{*}\end{array}$ & $\begin{array}{c}0.3(0.1 \\
0.7)^{*}\end{array}$ & $\begin{array}{c}0.7(0.1 \\
2.6)\end{array}$ & $\begin{array}{c}0.3(0.1 \\
0.7)^{*}\end{array}$ & $\begin{array}{c}0.4(0.1 \\
1.1)\end{array}$ & $\begin{array}{c}0.5(0.3 \\
0.9)^{*}\end{array}$ & $\begin{array}{c}0.6 \\
(0.2 \\
1.8)\end{array}$ & $\begin{array}{c}0.5 \\
(0.3,0.8)^{*}\end{array}$ & $\begin{array}{c}0.6(0.3 \\
1.2)\end{array}$ \\
\hline & Married & 1 & 1 & 1 & 1 & 1 & 1 & 1 & 1 & 1 \\
\hline \multirow{2}{*}{ 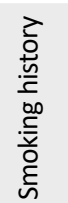 } & Yes & $\begin{array}{c}0.7(0.2 \\
1.9)\end{array}$ & $\begin{array}{c}1.1(0.4 \\
2.3)\end{array}$ & $\begin{array}{c}0.5(0.1 \\
2.5)\end{array}$ & $0.8(0.3,2.2)$ & $\begin{array}{c}0.4(0.1 \\
1.9)\end{array}$ & $1.7(0.9,3.3)$ & $\begin{array}{c}0.5 \\
(0.1 \\
2.5)\end{array}$ & $\begin{array}{c}0.9 \\
(0.5,1.6)\end{array}$ & $\begin{array}{c}0.6(0.2 \\
1.6)\end{array}$ \\
\hline & No & 1 & 1 & 1 & 1 & 1 & 1 & 1 & 1 & 1 \\
\hline
\end{tabular}

*P $<0.05$.

variables. Furthermore, the reference category for binary dependent variables, i.e. neck, shoulders, elbows, wrists/hands, knee, ankle, etc., was identified as "no prevalence". The strongest Odds Ratio (OR) for wrists/ hands pain was related to marital status $(\mathrm{OR}=0.35 ; 95 \%$ $\mathrm{CI}=0.16,0.77)$, i.e. three times higher than that. A history of physical exercise significantly decreased the annual prevalence of musculoskeletal symptoms. Table 3 also indicates the $\mathrm{OR}$ for elbows $(\mathrm{OR}=0.459 ; 95 \% \mathrm{CI}=0.234$, 0.902), wrists/hands ( $\mathrm{OR}=0.590 ; 95 \% \mathrm{CI}=0.369,0.941)$, and knee $(\mathrm{OR}=0.716 ; 95 \% \mathrm{CI}=0.523,0.981)$. Accordingly, physical exercise could reduce the MSDs prevalence to approximately 50\%. Additionally, a higher BMI was related to a higher prevalence of knee pain 
$(\mathrm{OR}=0.713 ; 95 \% \mathrm{CI}=0.520,0.977)$. Furthermore, the prevalence rate of neck pain, shoulders pain, writs/hands pain, Low Back Pain (LBP), knee pain, and ankle/foot pain has significantly increased in married workers.

The logistic regression analysis data of weekly prevalent musculoskeletal symptoms are presented as follows: Table 4 reveals a significant relationship between job experience and weekly prevalence of MSDs in the shoulder, as well as lower back and knee regions. The study participants who reported a job experience of $>5$ years were approximately twice as likely to encounter musculoskeletal discomfort in the shoulder $(\mathrm{OR}=0.5$; $95 \% \mathrm{CI}=0.3,0.9)$, lower back $(\mathrm{OR}=0.4 ; 95 \% \mathrm{CI}=0.3$, $0.7)$, and knee $(\mathrm{OR}=0.6 ; 95 \% \mathrm{CI}=0.4,0.8)$. Furthermore, there was a significant relationship between work hours per week and the prevalence of pain in the elbow area $(\mathrm{OR}=1.03 ; 95 \% \mathrm{CI}=1.01,1.06)$. There was also a significant relationship between musculoskeletal discomfort and exercise habits; such relations were observed between a lack of exercise and the prevalence of musculoskeletal discomfort in the elbow $(\mathrm{OR}=0.3 ; 95 \%$ $\mathrm{CI}=0.1,0.8)$, thigh $(\mathrm{OR}=0.3 ; 95 \% \mathrm{CI}=0.1,0.8)$, and knee $(\mathrm{OR}=0.6 ; 95 \% \mathrm{CI}=0.5,0.9)$. This finding indicates that the studied workers who exercised experienced a lower prevalence rate of elbow and thigh discomfort by about one-third; while workers who did not exercise reported a higher prevalence of discomfort in knees by about twothirds. The marital status of workers was significantly related to musculoskeletal symptoms. This relationship was significant for pain in neck $(\mathrm{OR}=0.4 ; 95 \% \mathrm{CI}=0.2$, $0.9)$, shoulders $(\mathrm{OR}=0.3 ; \mathrm{CI}=0.1,0.7)$, wrists $/$ hands $(\mathrm{OR}=0.3 ; 95 \% \mathrm{CI}=0.1,0.7)$, lower back $(\mathrm{OR}=0.5 ; 95 \%$ $\mathrm{CI}=0.3,0.9)$, and knee $(\mathrm{OR}=0.5 ; 95 \% \mathrm{CI}=0.3,0.8)$. Table 4 presents factors affecting the weekly prevalence of musculoskeletal symptoms.

\section{Discussion}

This survey determined the annual and weekly prevalence rates of MSDs among spinning workers. Moreover, we evaluated the relationship between specific occupational and demographic characteristics and the prevalence rate of the same variables among spinning workers in Najafabad City, Isfahan Province, Iran. Spinning industries are not frequently considered in the research. Besides, to our knowledge, there are few surveys on the prevalence of MSDs in spinning workers, particularly in countries with a great background in the textile industry. Most reports on MSDs in this industry concern weaving, knitting, and carpet production workers $[3,13,16,21,22]$.
Spinning workers appear to be at a high risk for developing WMSDs. We found that the annual prevalence of MSDs for one or more body regions in was high (74.4\%) among the explored spinning workers. The highest annual prevalent regions were the knees $(54.0 \%)$, lower back $(34.3 \%)$, and shoulders $(23.1 \%)$. In contrast, the most weekly prevalent regions were the knees (44.6\%), lower back (26.9\%), and ankles (15.9\%). Determining the prevalence pattern of a disorder is a major step in the prevention and subsequent treatment; however, research on spinner workers are scarce. Gamperiene et al. [23] reported an annual prevalence of $80 \%$ for the same, i.e. close to the current study results. They demonstrated the highest prevalence of complaints to be the legs (61\%), followed by the neck or arms (55\%), then the lower back (37\%). Again, these findings approximate those found in our results for the knees, shoulders, and lower back [23] In another cross-sectional study in a limited sample of a specific task of spinning (spinning in the sitting position), $80 \%$ of the study subjects have reported right shoulder pain, and $72.5 \%$ presented right wrist/hands pain and right knee pain [16]

In our study, the main tasks were in standing postures while working with the hands; therefore, the observed problems in the knee, lower back, and shoulders were anticipated [23]. The reported pain and discomfort depend on the adopted posture and task type. Dianat et al. signified working posture as an essential risk factor for creating neck pain, shoulders pain, and for the presence of LBP among handicraft workers who participated in hand sewing tasks [22].

Standing for long hours influences pressure distribution on the feet and increases trunk muscle fatigue; subsequently, it results in pain in the knees and low back among the spinning workers. In the study by Naz et al. [12], handloom weavers generally adopt a flexed sitting posture in a constrained position while working; therefore, the neck and lower back presented greater pain and discomfort [12]. Previous research among weaving and textile workers [24] reported the most prevalent affected regions as the lower back, ankle/feet, knees, and upper back, respectively [3, 25, 26]. Furthermore, Dianat et al. demonstrated that the prevalent regions affected in handicraft workers were the neck (57.9\%), lower back (51.6\%), and shoulders $(40.5 \%)$ [22]. The observed difference to our study can be related to the nature of the work which involves using the knee to brake the spinning machine; shifting the heavy loads by pushing; repeated prolonged static and walking postures, and inadequate rest. 
We also investigated the relationship between demographic characteristics and the prevalence of MSDs. Our results indicated a significant correlation between work experience, BMI, exercise status (physical exercise), marital status, and the annual prevalence of MSDs. BMI was a significant factor for knee pain during the last year $(\mathrm{OR}=0.71)$. In other words, among those with unhealthy BMI values, the odds of knee pain occurring was higher than that of the subjects with a healthy BMI. The detected significant effect of BMI was in line with the literature on general working populations [3, 27, 28].

Work experience is reported as a risk factor in the development of MSDs. The duration of employment is reported to be significantly associated with a high risk of MSDs, as measured by observational instruments [5, 29]. Similar to annual prevalence, the highest weekly prevalence of MSDs was observed in the knee and lower back with $44.6 \%$ and $26.9 \%$ frequencies, respectively. The explored workers who had $<5$ years of work experience experienced the statistically less significant prevalence of symptoms in the lower back $(\mathrm{OR}=0.472$; $\mathrm{CI}=0.308,0.724)$, shoulders $\quad(\mathrm{OR}=0.546 ; \mathrm{CI}=0.322$, $0.925)$, and knee $(\mathrm{OR}=0.599 ; \mathrm{CI}=0.414,0.868)$. Additionally, working hours per week significantly affected the prevalence of elbow pain $(\mathrm{OR}=1.030 ; \mathrm{CI}=1.001$, 1.060). Thus, workers with longer working hours were prone to encountering elbow pain.

Our results revealed that physical exercise history decreased the prevalence of MSDs, in particular, the symptoms of the elbow ( $\mathrm{OR}=0.4 ; \mathrm{CI}=0.2,0.9)$. Exercise habits significantly affect the health status of the whole musculoskeletal system [30]. A study performed in the hazelnut industry suggested that $88.6 \%$ of the workers had no exercise habits and the ratio of LBP was higher in the subjects who did not exercise [23]. Moreover, physical exercise history statistically decreased the weekly prevalence of MSDs, particularly symptoms of the elbows $(\mathrm{OR}=0.354 ; \mathrm{CI}=0.1,0.8)$, thigh $(\mathrm{OR}=0.3 ; \mathrm{CI}=0.1$, $0.8)$, and knee $(\mathrm{OR}=0.6 ; \mathrm{CI}=0.5,0.9)$. This finding was consistent with those of Serra et al. [31]; they reported a lower prevalence of MSDs for the trunk in the last week and last year, as well as for the upper limbs in the last year, compared with the controls [31].

Another result of this study was the effect of marital status on the weekly and annual prevalence of MSDs. Marital status was significantly correlated with neck, shoulders, wrist/hands, lower back, and knee pain. Both weekly and annual prevalence rates revealed relatively the same regions being affected. Comparing the results of the annual and weekly prevalence rates of musculo- skeletal symptoms indicated that the prevalence of pain in the wrist region was lower among single workers than their married counterparts. Marital status in the weekly survey presented a significant relationship with the prevalence of musculoskeletal pain in the shoulder, wrists, and knee; however, the prevalence of musculoskeletal symptoms in these regions was lower in the single workers. This may be due to the possibility that being married was associated with additional responsibilities, such as household activities, higher life stress, and lower rest time, making married workers more prone to MSDs, compared to their single counterparts [32, 33].

The obtained data suggested that a history of smoking provided no statistically significant effect on the prevalence of musculoskeletal symptoms; however, descriptive analysis data revealed that this factor increased the prevalence of shoulders and lower back symptoms. Some previous researchers have reported the relation between smoking habits and MSDs [34, 35]. The probable cause of the obtained result in our study was related to the low frequency $(7 \%)$ of smokers in this study.

The current study had some limitations. First, we only considered male workers in the spinning industry, as the workers in this industry were predominantly male. Therefore, the results cannot be generalized to all spinning workers. Second, we evaluated the WMSDs through interviews and questions; therefore, recall bias may have underestimated the results, especially in the annual prevalence. Another limitation of this study was employing the self-report questionnaire which usually is correlated with data bias. We included an adequate sample size in this cross-sectional study; however, exploring a larger sample size from different cities is recommended to present associations between the investigated variables. Future studies are required to concentrate on an epidemiological perspective, regarding musculoskeletal symptoms and other parameters, such as biopsychosocial risk factors in the spinning industry from a global perspective.

\section{Conclusion}

The presence of MSDs is common among textile workers, like spinners. Our findings suggested a high prevalence of musculoskeletal symptoms in the working spinner population of the textile industry. The most involved body regions were the knee and lower back, followed by the wrists concerning the one-year prevalence, and ankle/foot in the weekly prevalence. Consequently, any corrective action should focus on these specific areas and issues, with ergonomic intervention as a strong consideration. Furthermore, this study revealed that the weekly prevalence of musculoskeletal symptoms is significantly lower than that of the one-year prevalence rate. 


\section{Ethical Considerations}

\section{Compliance with ethical guidelines}

This study was approved by the Ethics Committee of the University of Social Welfare and Rehabilitation Sciences (Code: IR.USWR.REC.1397.133).

\section{Funding}

This article was extracted from the MSc. thesis of the first author at the Department of Ergonomics, University of Social Welfare and Rehabilitation Sciences.

\section{Authors' contributions}

Designed the study: Hamid Reza Mokhtarinia, Akbar Biglarian; Writing - review \& editing: Charles Philip Gabel; Conducted literature searches and provided summaries of previous research studies:Akram Shahbazi; Data analysis: Akbar Biglarian; Writing - original draft: Hamid Reza Mokhtarinia, Charles Philip Gabel; Approved by All authors.

\section{Conflict of interest}

The authors declared no conflicts of interest.

\section{References}

[1] Candan SA, Sahin UK, Akoğlu S. The investigation of workrelated musculoskeletal disorders among female workers in a hazelnut factory: Prevalence, working posture, workrelated and psychosocial factors. International Journal of Industrial Ergonomics. 2019; 74:102838. [DOI:10.1016/j.ergon.2019.102838]

[2] Mokhtarinia HR, Hosseini A, Maleki-Ghahfarokhi A, Gabel CP, Zohrabi M. Cross-cultural adaptation, validity, and reliability of the Persian version of the spine functional index. Health and Quality of Life Outcomes. 2018; 16(1):95. [DOI:10.1186/s12955-018-0928-5] [PMID] [PMCID]

[3] Telaprolu N, Anne SD. Physical and psychological work demands as potential risk factors for musculoskeletal disorders among workers in weaving operations. Indian Journal of Occupational and Environmental Medicine. 2014; 18(3):129-34. [DOI:10.4103/0019-5278.146910] [PMID] [PMCID]

[4] Shafeei A, Mokhtarinia HR, Maleki-Ghahfarokhi A, Piri L. Cross-cultural adaptation, validity, and reliability of the persian version of the Orebro musculoskeletal pain screening questionnaire. Asian Spine Journal. 2017; 11(4):520-30. [DOI:10.4184/asj.2017.11.4.520] [PMID] [PMCID]

[5] Berberoğlu U, Tokuç B. Work-related musculoskeletal disorders at two textile factories in Edirne, Turkey. Balkan Medical
Journal. 2013; 30(1):23-7. [DOI:10.5152/balkanmedj.2012.069] [PMID] [PMCID]

[6] Das D, Kumar A, Sharma M. A systematic review of workrelated musculoskeletal disorders among handicraft workers. International Journal of Occupational Safety and Ergonomics. 2020; 26(1):55-70. [DOI:10.1080/10803548.2018.1458487] [PMID]

[7] Birschel D. Lost-worktime injuries and illnesses: Characteristics and resulting time away from work, 2004. Benefits Quarterly. 2006; 22(2):61. https://search.proquest. com/openview/2f451c96510071e5a93bf447b8efcf6d/1?pqorigsite $=$ gscholar\&cbl $=4616$

[8] Yang S, Lu J, Zeng J, Wang L, Li Y. Prevalence and risk factors of work-related musculoskeletal disorders among intensive care unit nurses in China. Workplace Health \& Safety. 2019; 67(6):275-87. [DOI:10.1177/2165079918809107] [PMID]

[9] da Silva NC, Chaves TC, dos Santos JB, Sugano RMM, Barbosa RI, Marcolino AM, et al. Reliability, validity and responsiveness of Brazilian version of QuickDASH. Musculoskeletal Science and Practice. 2020; 48:102163. [DOI:10.1016/j. msksp.2020.102163] [PMID]

[10] Pirmand, R, Heidari A, Hashemipoor M, Talebi M, Saneikhah M, Shahirani Mousavi S, et al. [Relationship of ergonomic risk factors and musculoskeletal discomfort in a construction project at the refinery in Tehran (Persian)]. Journal of Sabzevar University of Medical Sciences. 2015; 22(3):324-33. http://jsums.medsab.ac.ir/article_567.html

[11] Almomani F, Alghwiri AA, Alghadir AH, Al-momani A, Iqbal A. Prevalence of upper limb pain and disability and its correlates with demographic and personal factors. Journal of Pain Research. 2019; 12:2691-700. [DOI:10.2147/JPR.S198480] [PMID] [PMCID]

[12] Naz H, Kwatra S, Ojha P. Prevalence of musculoskeletal disorders among handloom weavers of Uttarakhand: An ergonomic study. Journal of Applied and Natural Science. 2015; 7(1):102-5. [DOI:10.31018/jans.v7i1.571]

[13] Andersen JH, Gaardboe O. Musculoskeletal disorders of the neck and upper limb among sewing machine operators: A clinical investigation. American Journal of Industrial Medicine. 1993; 24(6):689-700. [DOI:10.1002/ajim.4700240605] [PMID]

[14] Montreuil S, Laflamme L, Tellier C. Profile of the musculoskeletal pain suffered by textile tufting workers handling thread cones according to work, age and employment duration. Ergonomics. 1996; 39(1):76-91. [DOI:10.1080/00140139608964435] [PMID]

[15] Meena ML, Dangayach GS, Bharadwaj A. Impact of ergonomic factors in Handicraft Industries. Proceedings of the International Conference of Mechanical, Production and Automobile Engineering. December 2011, Pattaya, Thailand. http:// psrcentre.org/images/extraimages/50.\%201211274.pdf

[16] Ikhar D, Deshpande V. Investigation of magnitude of musculoskeletal disorders among cotton spinning operators. Singapore: Springer; 2018. [DOI:10.1007/978-981-10-4980-4_7]

[17] Kaur G, Kaur M, Choudhary S. Knowledge regarding occupational hazards among factory workers of spinning mills. Baba Farid University Nursing Journal. 2018; 15(2):33-8. https://www.indianjournals.com/ijor.aspx?target=ijor:bfunj\& volume $=15 \&$ issue $=2 \&$ article $=006$ 
[18] Mokhtarinia H, Shafiee A, Pashmdarfard M. [Translation and localization of the Extended Nordic Musculoskeletal Questionnaire and the evaluation of the face validity and test-retest reliability of its Persian version (Persian)]. Iranian Journal of Ergonomics. 2015; 3(3):21-9. http://journal.iehfs. ir/article-1-215-en.html

[19] Anton D, Weeks DL. Prevalence of work-related musculoskeletal symptoms among grocery workers. International Journal of Industrial Ergonomics. 2016; 54:139-45. [DOI:10.1016/j.ergon.2016.05.006]

[20] Alaca N, Safran EE, Karamanlargil Aİ, Timucin E. Translation and cross-cultural adaptation of the extended version of the Nordic musculoskeletal questionnaire into Turkish. Journal of Musculoskeletal \& Neuronal Interactions. 2019; 19(4):472-81. [PMCID]

[21] Nag A, Vyas H, Nag PK. Gender differences, work stressors and musculoskeletal disorders in weaving industries Industrial Health. 2010; 48(3):339-48. [DOI:10.2486/indhealth.48.339] [PMID]

[22] Dianat I, Karimi MA. Musculoskeletal symptoms among handicraft workers engaged in hand sewing tasks. Journal of Occupational Health. 2016; 58(6):644-52. [DOI:10.1539/joh.150196-OA] [PMID] [PMCID]

[23] Gamperiene M, Stigum H. Work related risk factors for musculoskeletal complaints in the spinning industry in Lithuania. Occupational and Environmental Medicine. 1999; 56(6):411-6. [DOI:10.1136/oem.56.6.411] [PMID] [PMCID]

[24] Azevedo J, Costa S, Moreira-Silva I, Rodrigues S, Ventura $\mathrm{N}$, Cardoso R, et al. Prevalence of musculoskeletal symptoms among workers of a portuguese textile industry: Association with body mass index and work position. In: Arezes PM, Baptista JS, Barroso MP, Carneiro P, Cordeiro P, Costa N, et al, editors. Occupational and Environmental Safety and Health II. $1^{\text {th }}$ ed. Berlin: Springer; 2020.[DOI:10.1007/978-3030-41486-3_49]

[25] Chavalitsakulchai P, Shahnavaz H. Musculoseletal disorders of female workers and ergonomics problems in five different industries of a developing country. Journal of Human Ergology. 1993; 22(1):29-43. [PMID]

[26] Singh MB, Fotedar R, Lakshminarayana J. Occupational morbidities and their association with nutrition and environmental factors among textile workers of desert areas of Rajasthan, India. Journal of Occupational Health. 2005; 47(5):371-7. [DOI:10.1539/joh.47.371] [PMID]

[27] Wang T, Zhao YL, Hao LX, Jia JG. Prevalence of musculoskeletal symptoms among industrial employees in a modern industrial region in Beijing, China. Chinese Medical Journal. 2019; 132(7):789-97. [DOI:10.1097/CM9.0000000000000165] [PMID] [PMCID]

[28] Viester L, Verhagen EALM, Hengel KMO, Koppes LLJ, van der Beek AJ, Bongers PM. The relation between body mass index and musculoskeletal symptoms in the working population. BMC Musculoskeletal Disorders. 2013; 14:238. [DOI:10.1186/1471-2474-14-238] [PMID] [PMCID]

[29] Lemasters GK, Atterbury MR, Booth-Jones AD, Bhattacharya A, Ollila-Glenn N, Forrester C, et al. Prevalence of work related musculoskeletal disorders in auctive union carpenters. Occupational and Environmental Medicine. 1998; 55(6):421-7. [DOI:10.1136/oem.55.6.421] [PMID] [PMCID]
[30] Gabel CP, Mokhtarinia HR, Hoffman J, Osborne J, Laakso EL, Melloh M. Does the performance of five back-associated exercises relate to the presence of low back pain? A crosssectional observational investigation in regional Australian council workers. BMJ Open. 2018; 8(8):e020946. [DOI:10.1136/ bmjopen-2017-020946] [PMID] [PMCID]

[31] Serra MVGB, Camargo PR, Zaia JE, Tonello MGM, Quemelo PRV. Effects of physical exercise on musculoskeletal disorders, stress and quality of life in workers. International Journal of Occupational Safety and Ergonomics. 2018; 24(1):62-7. [DOI:10.1080/10803548.2016.1234132] [PMID]

[32] Ge H, Sun X, Liu J, Zhang C. The status of musculoskeletal disorders and its influence on the working ability of oil workers in Xinjiang, China. International Journal of Environmental Research and Public Health. 2018; 15(5):842. [DOI:10.3390/ ijerph15050842] [PMID] [PMCID]

[33] Barzideh M, Choobineh AR, Tabatabaee H. Job stress dimensions and their relationship to musculoskeletal disorders in Iranian nurses. Work. 2014; 47(4):423-9. [DOI:10.3233/ WOR-121585] [PMID]

[34] Palmer KT, Syddall H, Cooper C, Coggon D. Smoking and musculoskeletal disorders: Findings from a British national survey. Annals of the Rheumatic Diseases. 2003; 62(1):33-6. [DOI:10.1136/ard.62.1.33] [PMID] [PMCID]

[35] Micheletti JK, Bláfoss R, Sundstrup E, Bay H, Pastre CM, Andersen LL. Association between lifestyle and musculoskeletal pain: Cross-sectional study among 10,000 adults from the general working population. BMC Musculoskeletal Disorders. 2019; 20(1):609. [DOI:10.1186/s12891-019-3002-5] [PMID] [PMCID] 